Article

\title{
Solidarity in the Public Sphere: A Discourse Network Analysis of German Newspapers (2008-2017)
}

\author{
Stefan Wallaschek ${ }^{1, *}$, Christopher Starke ${ }^{2}$ and Carlotta Brüning ${ }^{2}$ \\ ${ }^{1}$ Institute of Social Sciences, University of Hildesheim, 31141 Hildesheim, Germany; E-Mail: wallaschek@uni-hildesheim.de \\ 2 Department of Social Sciences, University of Düsseldorf, 40225 Düsseldorf, Germany; \\ E-Mails: christopher.starke@uni-duesseldorf.de (C.S.), carlotta.bruening@uni-duesseldorf.de (C.B.)
}

* Corresponding author

Submitted: 31 October 2019 | Accepted: 1 March 2020 | Published: 2 June 2020

\begin{abstract}
Multiple crises in the EU have sparked a renaissance of the concept of solidarity. However, discursive approaches to solidarity and the public understanding of solidarity have hardly received scholarly attention. Empirical research on solidarity is rather centered on welfare institutions as well as on individual attitudes and behavior. To shed new light on solidarity in public discourse, we investigate in which policy fields the term is most often used, which actors refer to it and how different types of solidarity are covered in the German public discourse. We investigate the coverage of solidarity in four German newspapers (Die Welt, Frankfurter Allgemeine Zeitung, Süddeutsche Zeitung, Die Tageszeitung) from 2008 to 2017. By deploying the discourse network methodology with 306 claims in 230 news articles, we analyze the co-occurrence of actors and issues over time. Our results indicate a varying set of issues in which solidarity occurs, a rather stable actor visibility, across time and a context-dependent use of different types of solidarity. Government actors, civil society actors as well as citizens drive the solidarity discourse showing that institutional as well as non-institutional actors make use of solidarity in their public actions regarding political protest, financial issues and migration. The study provides novel insights into the interdependence of actor and issue visibility and sheds new light on solidarity in media discourses.
\end{abstract}

\section{Keywords}

discourse network analysis; Germany; newspapers; public discourses; public sphere; solidarity

Issue

This article is part of the issue "Policy Debates and Discourse Network Analysis" edited by Philip Leifeld (University of Essex, UK).

(C) 2020 by the authors; licensee Cogitatio (Lisbon, Portugal). This article is licensed under a Creative Commons Attribution 4.0 International License (CC BY).

\section{Introduction}

Solidarity and crisis are interrelated. The recent debates about the Euro crisis and the migration crisis have sparked a renaissance of the concept of solidarity in general and the crisis-solidarity nexus in particular (Wallaschek, 2019a). The reason for this renewed interest in solidarity lies in its ability to solve social problems by ensuring cooperation and mutual support even in times of crisis (Lindenberg, 1998). Thus, whenever a crisis gains public attention; there arises the demand for solidarity to overcome it. Yet, what different actors actu- ally refer to when they call for more solidarity remains highly contested (Brändle, Eisele, \& Trenz, 2019).

In recent years, scholarly work on solidarity has led to theoretical as well as empirical advances in the research field (Banting \& Kymlicka, 2017; Della Porta, 2018; Lahusen \& Grasso, 2018; Sangiovanni, 2015). That is, scholars have investigated solidarity in various contexts, policy fields and from varying theoretical perspectives. The analysis of "institutionalised solidarity" (Gelissen, 2000 ) in national welfare states, and the investigation of solidary attitudes, opinions and actions in the EU have dominated the academic literature (Ciornei \& Recchi, 
2017; Gerhards, Lengfeld, Ignácz, Kley, \& Priem, 2020; Lahusen \& Grasso, 2018; van Oorschot, 2000). Discourses about solidarity in public spheres are still underexplored. However, the discursive approach allows one to investigate an everyday understanding of the rather abstract concept of solidarity, shedding light on how different actors contest the notion of solidarity in public debates. Previous research has largely focused on how specific issues are linked to solidarity or how solidarity is framed in certain European crises (Brändle et al., 2019; Closa \& Maatsch, 2014; Wallaschek, 2020a; Williams \& Toula, 2017).

Yet, these studies have often assumed rather than empirically investigated the link between crisis and calls for solidarity by only investigating specific crises instead of the broader public discourse. Furthermore, former work has looked at short periods of time in which a particular crisis occurred. Hence, we will fill this research gap by investigating the following research question: How is the term 'solidarity' contested in the public discourse? More precisely, this article sheds light on the nexus between actors, issues and solidarity types. We deploy the discourse network analysis (Leifeld, 2016) to examine how actors refer to different types of solidarity regarding various issues. Moreover, we track how these discourse networks change in German newspapers from 2008 to 2017. In doing so, we add to the literature in two major ways. First, we scrutinize different types of solidarity by analyzing how different actors refer to solidarity with regard to different issues in the public debate. Second, we go beyond the existing literature on solidarity contestation by investigating the public discourse without focusing on specific crises and by providing a longitudinal analysis of how the coverage of solidarity changed over a ten-year period.

\section{Concepts of Solidarity}

Solidarity has been a key concept in the social sciences (Lindenberg, 1998). Scholars posit that without solidarity "no meaningful political community can exist" (Auer, 2014, p. 329), as societies would fail to maintain stability and eventually fall apart. The reason for the pivotal importance of solidarity lies in its ability to solve social problems in situations when other control mechanisms such as coercion or incentives fail (Hechter, 1988; Lindenberg, 1998). In his seminal work, Durkheim (1965) argued that solidarity refers to individuals who regulate their "actions by something other than the promptings of [their] own egoism" (p. 331). Inspired by Durkheim's work, the literature on solidarity has diversified, leading to a plethora of novel theoretical approaches (Banting \& Kymlicka, 2017; Bayertz, 1999; Hechter, 1988; Sangiovanni, 2015). However, the nature of solidarity remains highly contested. The debate largely centers on five key points (de Beer \& Koster, 2009): (1) The level of solidarity refers to the distinction between solidarity organized by institutions (macro-level) and solidarity between individual actors based on specific attitudes or behaviors (micro-level; Tranow, 2019); (2) The role of voluntariness alludes to the debate about the motivation for acting in solidarity. While some authors argue that "solidarity is a choice" (de Beer \& Koster, 2009 , p. 21), others posit that it can also be coerced, as is the case with welfare state arrangements (van Oorschot, Arts, \& Halman, 2005). Accordingly, some scholars locate solidarity between obligation and general acts of generosity (Auer, 2014; Taylor, 2015) or between insurance and charity (Van Parijs, 2017); (3) The scope of solidarity describes the circle of people with whom one shows solidarity. In other words, "who is included and who is excluded" (Stjernø, 2009, p. 16). Solidarity can therefore be conceived as concentric circles ranging from the interpersonal level (e.g., family, friends, neighborhood) to the supranational level (e.g., EU, world; Althammer, 2019; Michailidou \& Trenz, 2018). Arguably, solidarity even extends to non-existent groups such as future generations or non-human entities such as animals or the environment; (4) The form of solidarity refers to the specific nature of the resources that are being redistributed or shared. Solidarity is primarily expressed via time (e.g., participating in demonstrations) or money (e.g., donations). However, it can also be shown in kind (e.g., blood donations, communication; de Beer \& Koster, 2009); and (5) The role of reciprocity alludes to the question of whether solidarity is based on mutuality among members of a common group or whether it can be shown to external groups without direct or indirect compensation (Althammer, 2019; Thome, 1999).

In this article we focus on the latter aspect because the philosophical literature on solidarity convincingly argues that reciprocal relations are a key element of solidarity, which distinguishes it from related concepts such as charity and altruism (Bayertz, 1999; Wildt, 1999). In contrast to these concepts, solidarity contains the expectation to help others but also to receive help if the situation of both actors were reversed (Gouldner, 1960). Thus, the key question is not whether a reciprocal relationship exists, but rather how the reciprocal relationship is shaped. For instance, Bierhoff and Küpper (1999) distinguish between solidarity based on common interests and solidarity based on the interests of others. The former alludes to mutual support within a group of people who share the same fate or goals (in-group solidarity). Actors join forces to achieve a common goal they would otherwise be unable to attain. Take for example trade unionists who go on strike to fight for better wages. Solidarity based on the interests of others is directed at an external group (out-group solidarity). This form of solidarity is "unidirectional" (Althammer, 2019, p. 15) or "asymmetrical" (Thome, 1999, p. 122). To illustrate this form of solidarity, think for example of volunteers offering support to victims of a natural disaster.

To denote these symmetrical and asymmetrical relationships between those who give solidarity and those who receive it, O'Neill (2002, p. 201) introduced the 
terms "solidarity among" and "solidarity with." It is often argued that especially in times of crisis, "solidarity among' is a much stronger social bond compared to 'solidarity with' because it is based on some kind of similarity or shared identity. For that reason, calls for more solidarity in the EU have often been accompanied by a call for more European identity. However, 'solidarity with' also has important societal implications. For instance, it ensures support for those people, groups or countries who are in need and require help. On the flipside, it can also perpetuate existing power structures in society as:

A dependence upon good will and the readiness of others to help creates second-class citizens who are not in a position to associate with their benefactors on the same level, and certainly not to oppose them politically. (Bayertz, 1999, p. 23)

Brändle et al. (2019, p. 711) argue that the term solidarity is highly "contested and marked by political struggle since it is tied to questions about the constitution of the political community and what is considered appropriate behavior and practice." The conceptual distinction between 'solidarity among' and 'solidarity with' guides our analysis as it is well suited to detect solidarity contestations between different actors with respect to certain issues discussed in the public sphere.

\section{Public Discourses on Solidarity}

As Brändle et al. (2019, p. 709) point out, "solidarity contestations have become highly salient in the news media." However, a discursive perspective on solidarity has only recently gained scholarly attention (Brändle et al., 2019; Closa \& Maatsch, 2014; Wallaschek, 2020b). The advantage of the discursive approach is that it assumes that solidarity is not a predefined and stable concept, but rather that it is constantly reconstructed in public debates. It provides insights about an everyday understanding of the term and therefore offers a bottom-up perspective to investigate solidarity. In other words, it takes into account what different actors who publicly speak about solidarity refer to when they use the term. In modern societies, those discourses primarily take place in mediated public spheres (Dahlgren, 2002; Habermas, 2006). In this study, we focus on the dominant issues and actors in the public discourse about solidarity.

\subsection{Issues}

Solidarity is often evoked in times of crisis (Michailidou \& Trenz, 2018). Even though studies have extensively looked at solidarity in the context of specific crises such as the Euro crisis or Europe's migration crisis (Gerhards et al., 2020; Grimmel \& Giang, 2017; Lahusen \& Grasso, 2018), the specific link between solidarity and crisis remains largely unexplored. On the one hand, solidarity is regarded as a means to solve societal problems through the redistribution or bundling of resources (Kolers, 2012; Stjernø, 2009). For instance, by cooperating, EU member states can implement policies that they would otherwise be unable to advance. On the other hand, crises may undermine solidarity as they tend to fuel populism and reinforce national stereotypes or xenophobic tendencies (Lahusen \& Grasso, 2018). The European debt crisis as well as the migration crisis serve as two prominent cases in point to support this claim (Sierp \& Karner, 2017). Wallaschek (2019a, p. 261) concludes:

It seems that studying solidarity requires a crisis situation, because a perceived threat or danger might influence claims and attitudes towards solidarity....What is the state of solidarity in non-crisis periods and how do solidary practices, attitudes and claims change before, in and after such a crisis?

In light of this expected but understudied solidaritycrisis nexus, we focus on the question of how solidary claims change over time and whether crises influence how the news media covers solidarity. More precisely, we expect the discourse on solidarity to be dominated by issues related to key crises. For the European context, the European debt crisis and the migration crisis might be the most dominant issues related to solidarity. Furthermore, we expect that international terrorism and climate change are key issues that have dominated the public discourse in the past decade and that have been associated with solidarity (Kleinen-von Königslöw, Post, \& Schäfer, 2019; Luengo \& Ihlebæk, 2019).

\subsection{Actors}

In addition to the issues related to solidarity, this study puts emphasis on the different actors who drive the public discourse on solidarity. More precisely, we shed light on solidarity contestations, that is, which form of solidarity actors refer to: 'solidarity among' or 'solidarity with.' On a general note, empirical research has shown that elites are prominently represented in media discourses, while citizens only play a marginal role (Thorbjørnsrud \& Ustad Figenschou, 2016). As Lahusen, Kousis, Kiess, and Paschou (2016, p. 544) convincingly argue:

Discourses are dominated also in times of crisis by key policy actors...and they marginalize civil society organizations and citizens groups. Hence the crisis is not at all a window of opportunity that expands the range of groups and claims and disrupts established discourse communities.

Most content analyses explicitly dealing with solidarity contestations in the public discourse seem to support this finding. Using the migration crisis and the Euro crisis as cases in point, Wallaschek (2019b, 2020a) finds that political elites, especially national executives and party actors, are strongly represented in the print media. Along 
similar lines, Brändle et al. (2019) investigate the media coverage about the migration crisis in four European countries. They suggest that state actors made over $70 \%$ of all analyzed political claims, while all other actors account for only $30 \%$ of political claims. Looking at the solidarity contestations in parliamentary debates about the European debt crisis, Closa and Maatsch (2014) demonstrate that party oppositions use solidarity claims to criticize the government for its lack of solidarity with debtor member states. To derive expectations regarding the use of 'solidarity among' or 'solidarity with,' we mainly draw on the findings of Brändle et al. (2019). Their results suggest that state actors tend to promote exclusive notions of solidarity, ergo 'solidarity with,' while societal actors primarily refer to inclusive forms of solidarity, ergo 'solidarity among.' Given the strong empirical evidence about solidarity contestations, we assume similar results will be found when looking at the public discourse more broadly. Thus, in this study we do not focus on one specific crisis, but rather investigate the general public debate about the term solidarity in the past decade.

\section{Method}

To answer the research question, we conducted a standardized content analysis of 306 claims in 230 articles from four national quality newspapers in Germany published between 2008 and 2017: Die Tageszeitung, Süddeutsche Zeitung, Frankfurter Allgemeine Zeitung, and Die Welt. All selected newspapers range among the largest daily newspapers in Germany in terms of circulation and account for a total of 745,522 copies per day (IVW, 2019). All investigated newspapers are influential opinion-forming media outlets and span the journalistic political spectrum: The Die Tageszeitung is a left-leaning newspaper, the Süddeutsche Zeitung is a center-left newspaper, the Frankfurter Allgemeine Zeitung is a center-right newspaper, and the Die Welt is a conservative newspaper (Eilders, 2002). The material was accessible via the database LexisNexis (Die Tageszeitung, Die Welt) or via the databases of the respective publishers (Süddeutsche Zeitung, Frankfurter Allgemeine Zeitung).

\subsection{Sample}

The articles of this study were defined by two criteria. First, all articles were published in the selected newspapers between 2008 and 2017. The time period was chosen because the global financial crisis in 2008 triggered the subsequent European debt crisis and European migration crisis during which the term 'solidarity' was increasingly popularized (Wallaschek, 2019b). Second, all articles contained at least one of the following words in the title or subtitle: 'solidarity,' 'solidary,' 'solidaristic.' The population contained a total of 2,234 articles: Die Tageszeitung (685 articles, 30.6\%), Süddeutsche Zeitung (906 articles, 40.5\%),
Frankfurter Allgemeine Zeitung (463 articles, 20.7\%), Die Welt (180 articles, $8.1 \%)$. To draw a sample for the manual standardized content analysis, we created artificial weeks starting with Monday of the first calendar week of 2008, followed by Tuesday of the second calendar week of 2008 and so on. By this, we reduced the final sample to a manageable amount of 300 articles and ensured that all years, months, and weekdays were equally represented. From the selected weeks, we downloaded all articles that met the selection criterion outlined above: Die Tageszeitung (96 articles, 32\%), Süddeutsche Zeitung (120 articles, 40\%), Frankfurter Allgemeine Zeitung (64 articles, 21.3\%), Die Welt (20 articles, 6.7\%). Thus, our sample roughly matches the population in terms of distribution among the four selected newspapers.

\subsection{Unit of Analysis: Statements}

For the discourse network analysis, we used statements as the primary unit of analysis. We coded the newspapers' material by following the claims-making approach (Koopmans \& Statham, 1999) that defines a claim as "the purposive and public articulation of political demands, calls to action, proposals, criticisms or physical attacks, which, actually or potentially, affect the interests or integrity of the claimants and/or other collective actors" (Koopmans, 2007, p. 189). In each claim we categorized: (1) the actor voicing a statement, its institutional/organization affiliation, (2) the issue or context which the statement refers to, and (3) the position of the statement. Coders were instructed to code a statement only if all categories were available in the newspaper article. For each statement, we further coded the solidarity relation ('solidarity among' or 'solidarity with'). 70 articles were excluded from the sample because they did not contain an actor and were therefore ineligible for subsequent data analysis. In total, we coded 306 statements in 230 articles.

Figure 1 gives an overview of the number of coded statements in each newspaper as well as the distribution per year. It shows a rather similar distribution of statements for the Süddeutsche Zeitung and the Die Tageszeitung since 2011 while the Frankfurter Allgemeine Zeitung and the Die Welt show different patterns. In comparison to the center-left Süddeutsche Zeitung and left-leaning Die Tageszeitung, we find an almost inverse distribution for the Frankfurter Allgemeine Zeitung from 2012-2015 and hardly any changes in the number of statements for the right-conservative Die Welt newspaper. Nonetheless, the year 2015 marks the peak in the number of coded statements in three of the four newspapers (the exception is the Frankfurter Allgemeine Zeitung). This is related to Europe's migration crisis and a broad debate on solidarity in the context of immigration, asylum and refugees (see Section 4.3). 


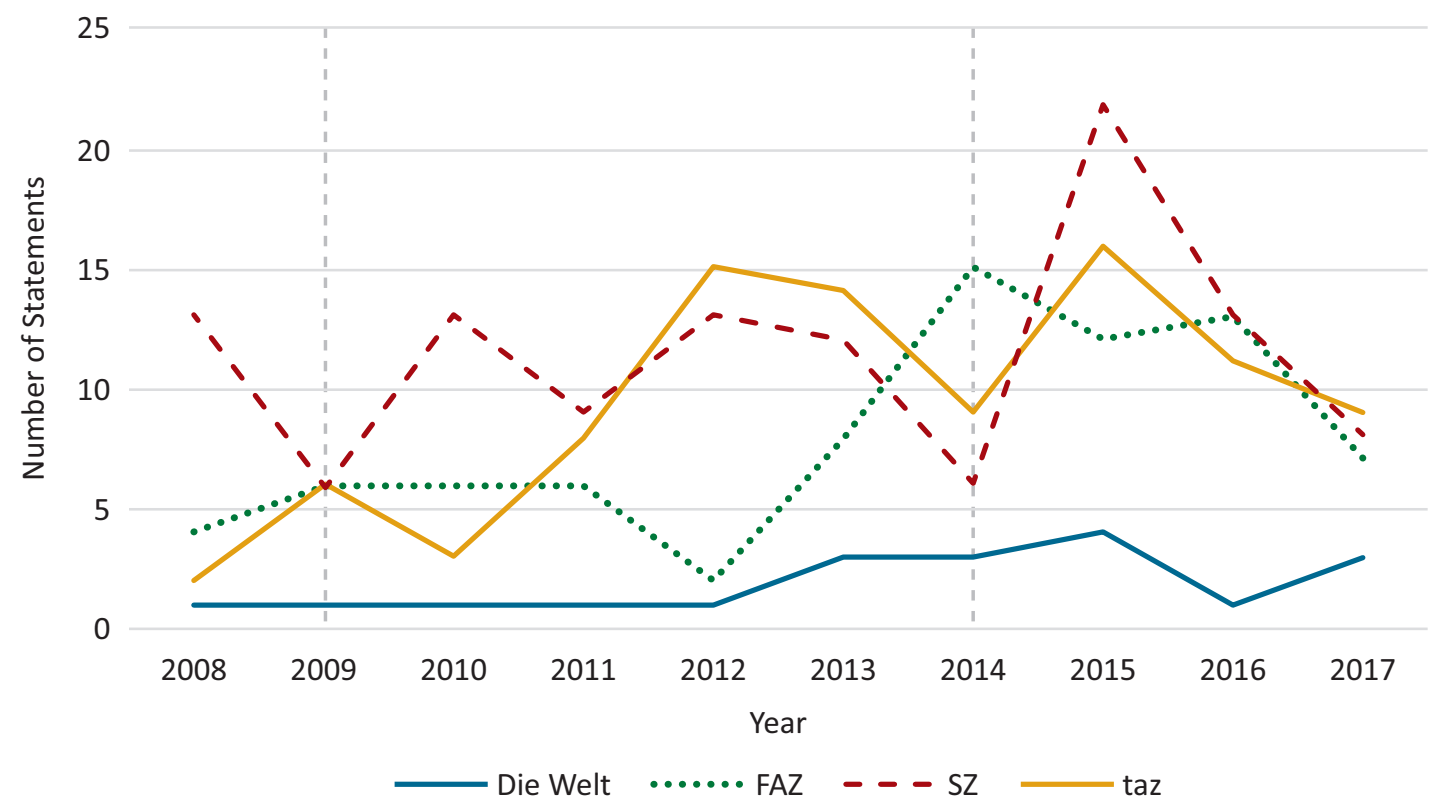

Figure 1. Number of statements per newspaper and year.

\subsection{Measures}

\subsubsection{Formal Categories}

At the article level we coded the name of the newspaper, the publishing date and the length of the article (in total words).

\subsubsection{Actors}

We coded an actor if he/she is directly or indirectly quoted in the article and takes a position on a solidarity issue. It is irrelevant whether this is an individual actor (e.g., Angela Merkel, Donald Tusk) or a collective actor (e.g., European Central Bank, Greenpeace). As it was impossible to compile a complete list of all potential actors, we instructed coders to note the name of the actors. For individual actors, we further coded the organization they work for or represent. In case the organization was not mentioned in the article, coders were assigned to conduct an internet search. Moreover, we coded the organization type of the actor voicing a statement. For that, we compiled a list of actors according to their function (e.g., Angela Merkel as member of the national government).

\subsubsection{Issue}

To code the solidarity issue to which the actors of a statement refer, we opted for a stepwise process. First, coders were instructed to describe the issue in one sentence (e.g., solidarity with Syrian refugees in the EU). Second, the authors grouped the issues into codes. All coders had to unanimously agree to assign the description of the issues to specific issue codes. In case of disagreement, the coders deliberated about the issue code until a com- mon agreement was found (e.g., solidarity with Syrian refugees in the EU as a migration issue).

\subsubsection{Position}

We further coded whether the actor of a statement evaluates the issue positively or negatively. For instance, actors may demand more solidarity among EU member states to solve the European debt crisis. Yet, actors may criticize EU member states for acting in solidarity. If a statement could not be clearly assigned to a position, the statement was not coded. However, if the actor of a statement took a balanced position and positive as well as negative evaluations could be clearly identified, then the statements were coded separately (e.g., one time as positive, one time as negative). Since approximately $90 \%$ of all claims are coded positively, thus, almost all actors support any kind of solidarity on different issues, we do not investigate this category any further in our analysis.

\subsubsection{Solidarity Relation}

Drawing on the seminal distinction drawn by O'Neill (2002), we further coded whether a statement refers to 'solidarity among' or 'solidarity with.' For that, coders were provided with detailed explanations of both solidarity types. In total, 44\% (135 statements) of all statements are 'solidarity among' claims, referring to solidarity within a social group. On the one hand, if a German politician demands more solidarity between NATO members, it is coded as 'solidarity among' because the statement refers to solidary actions among NATO member states. On the other hand, if a German civil society organization claims solidarity with journalists in Iraq or Turkey because they are persecuted, then we coded it as 'solidarity with' ( $56 \%$ of all statements/171 statements). 


\subsection{Coding Procedure and Pretest}

An extensive pretesting period was needed to ensure sufficient reliability of the codebook. For that, we provided coders with extensive coding instructions and practical examples for each variable. In a first step, we discussed the codebook with German native speaking coders, using two exemplary articles. As a result of this procedure, we condensed coding categories, adjusted problematic categories, clarified coding instructions, and added examples to minimize potential ambiguity. In a second step, we drew a random sample of 10 articles for an extensive pretest with four coders. The pretest revealed sufficient intercoder reliability. For all coded categories, the agreement between coders was $78 \%$.

Afterwards, we computed a discourse network analysis (Leifeld, 2016; Leifeld \& Haunss, 2012), which brings together content-oriented and actor-centered coding methods. Thus, it sheds light on the co-occurrence of issues and actors in public debates. The discourse network analysis combines discourse analysis and social network analysis and is, in its fundamental network structure, a bipartite network. An actor and an issue are linked if the actor refers to the issue in its claim. Based on this network structure, one-mode projections can be computed to analyze the actor network or issue network. For our study, we use the two-mode network structure to study the discourse network dynamics regarding changing actor visibilities and issue presence. The difference between the two types of solidarity ('solidarity among' vs. 'solidarity with') is visualized as two different edges and displays a multiplex network. This demonstrates which actor uses what kind of solidarity in relation to which issue and whether we find patterns that are related to the overall solidarity discourse. The eigenvector centrality of actors and issues is calculated (Bonacich, 1987). It not only counts the number of edges a node has, but also analyzes whether the node is linked to other central nodes in the network structure. The eigenvector centrality scale runs from 0 to 1 and the higher the value, the more central is the node in the network.

\section{Findings and Discussion}

In our empirical analysis, we proceed in three steps. First, we map the solidarity discourse network and show the interconnectedness of actors and issues that they address in their statements. We highlight what type of solidarity relation is linked to which actors and issues. Second, we visualize the discourse network in three different time periods to identify changes in the (co-)occurrence of actors and issues over time. Lastly, we focus on the issue centrality in order to show the discursive dynamics in the German solidarity debate.

\subsection{Mapping the Solidarity Discourse}

The discourse on solidarity shows a great variance of actors and issues that are discussed in the sampled print media. A total of 16 different issues have been coded and 21 functional actor groups have been identified in the debate. This results in 37 nodes and 306 edges in the discourse network. Government actors, civil society groups as well as citizens are the most central groups in the discourse (see Table A3 in the Supplementary File) because they claim various issues in their multiple statements. While we expected the presence of government actors, the visibility of civil society groups and especially citizens demonstrates that the debate on solidarity alludes to less institutionalized actors. The low centrality of international and European actors reveals that the German discourse on solidarity is hardly Europeanized on the actor dimension.

Regarding the type of edges, we identified 135 'solidarity among'-edges and 171 'solidarity with'-edges which shows a rather balanced use of both solidarity types in the discourse. However, they are used by different actors and refer to different issues (see Figure 2 and Table A5 in the Supplementary File). We have divided the network along the different solidarity relations. While the upper discourse network shows the 'solidarity among'-relations, the lower network graph visualizes the 'solidarity with'-discourse networks. The size of the nodes and labels is based on eigenvector centrality. The two networks show two crucial findings. On the one hand, both networks show similarities regarding the strong visibility of government actors and an important reference to migration (among other issues). Hence, national executive actors are key actors in the discourse and predominantly refer to in-group solidarity. As such, these statements targeted issues on security (NATO membership) or financial issues (European debt crisis). Migration is one of the most important issues in the solidarity discourse and is considered to be relevant for both solidarity types, solidarity among members of a group and solidarity with others (beyond the group boundaries; see also the centrality scores in Table A2 in the Supplementary File). On the other hand, the two networks have unique actor and issue appearances. While the government actors are strongly visible in both networks, the 'solidarity with'-discourse has more actors who are visible and not marginalized than the discourse on 'solidarity among.' In particular, citizens and civil society groups are more present in the 'solidarity with'-discourse and this is underlined by the high visibility of the two issues of political protest and civic rights and freedom. Actors-especially civil society groups-claiming to act in solidarity with other groups because they support protest and social movements in other countries, stand up for the rights of minorities and marginalized groups or want to protect the rights and freedoms of the people. When these actors engage in the debate on solidarity, they mainly refer to solidarity beyond their own group and mobilize the public to show solidarity with others such as the Russian punk band Pussy Riot, Occupy Wall Street in New York or the protest and democratization movements in the Arab Spring. 
Discourse: solidarity among

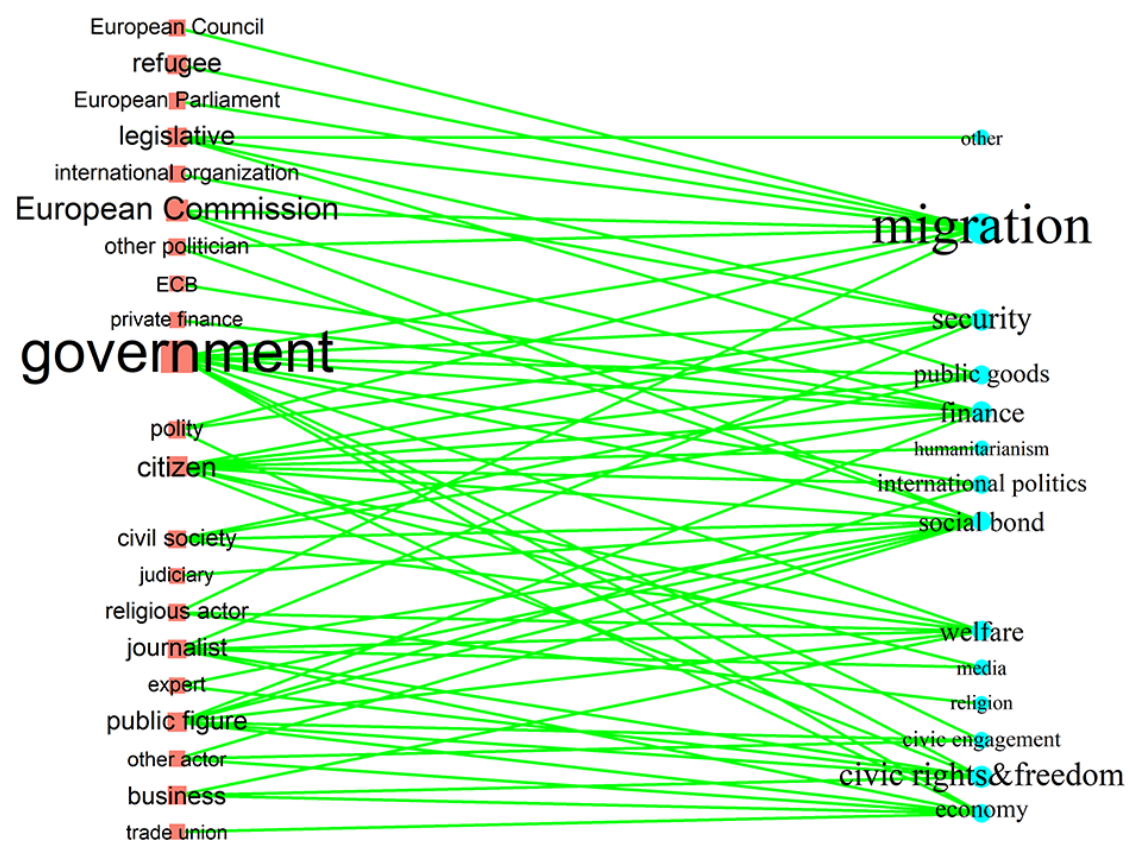

Discourse: solidarity with
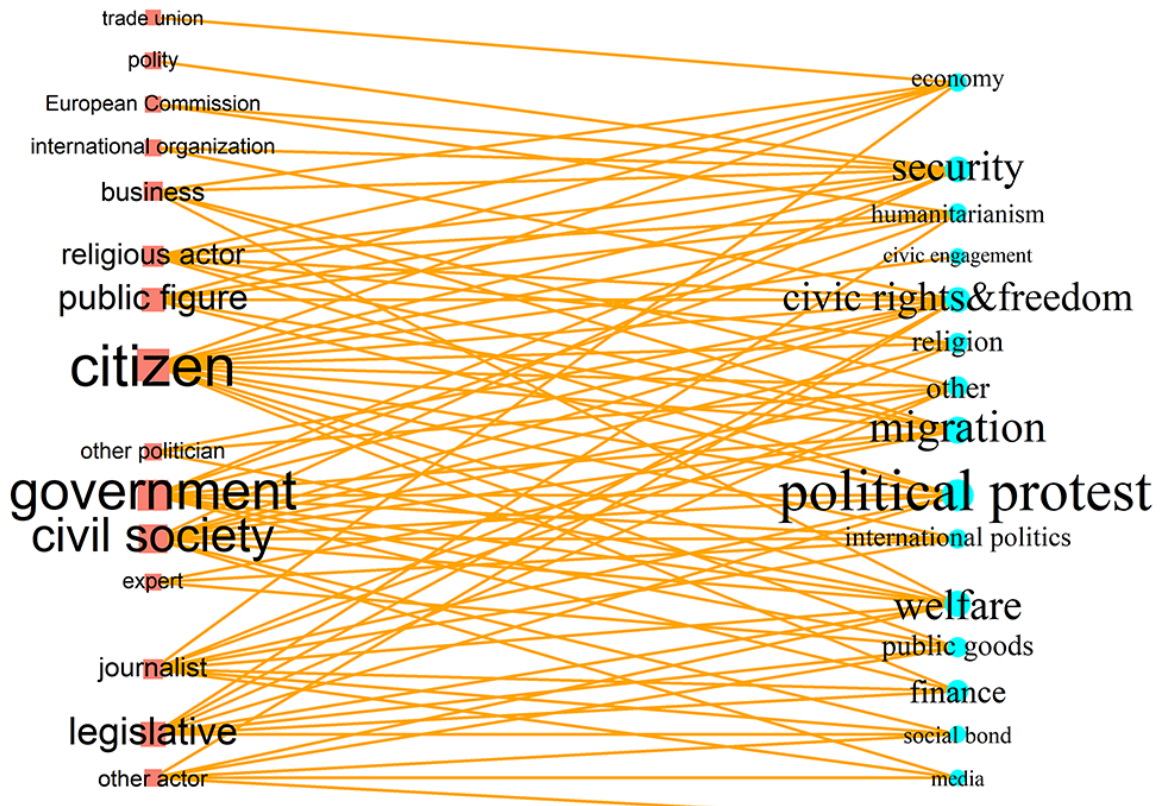

Figure 2. Solidarity relations in the German discourse network, 2008-2017. Note: The red squares are actor groups and the blue circles are issues. The bigger the node and the label, the more central the node is in the discourse network, based on eigenvector centrality. The green edges are 'solidarity among' statements while the orange edges are 'solidarity with' statements. The edge weight is dichotomized in both networks, meaning that the weight of the edges is either one (existing dyad) or zero (non-existing dyad).

\subsection{Issue Centrality in the Solidarity Discourse}

The next step of our analysis differentiates the solidarity discourse into three time periods. Following our initial expectation that times of crisis are times of solidarity and that they might relate to different types of solidarity, we computed the discourse networks for three time periods: the Global Recession in the years 2008-2009 (Figure 3), the Euro crisis from 2010 to 2014 (Figure 4), and the migration crisis in Europe from 2015 to 2017 (Figure 5). By 
dividing the discourse into three distinct time periods, we can trace the presence of actors and issues over time and show the changing visibility of actors, issues and solidarity relations. The bigger the labels and nodes in the network, the more central they are in the network. The different network structures demonstrate the dynamics and shifts in the discourse.

Even though we expected a debate on solidarity in the context of the Global Recession, Figure 3 shows a rather unconnected solidarity discourse. There are several issues that gained public attention such as emphasizing solidarity among NATO members (security), calls for solidarity actions with the poor and marginalized groups in need (welfare) or diverse calls for solidarity with protest movements across the globe (political protest). Interestingly, the global financial crisis was not prominently covered as an issue of solidarity. Moreover, the distribution of claims on external (solidarity with) or internal (solidarity among) solidarity is almost even. Therefore, we conclude that the first time period has not supported our expectation of a unifying crisis-solidarity nexus; rather it has shown that calls for solidarity are raised in very different contexts. The second time period (2010-2014, Figure 4) not only shows an increasing number of edges and nodes in the discourse network, but also suggests that these actors and issues are more interconnected. We identify three key issues in the solidarity debate: claims on solidarity in the Euro crisis, solidarity calls regarding protest movements, and a diverse set of appeals to solidarity that refer to the protection and defense of civic rights. The appearance of these issues supports the link between crisis and solidarity, but underlines that multiple, simultaneous crisis experiences resonate in the public. Instead of having one debate on solidarity, the discourse is separated into different debates that refer to specific aspects and issues. The solidarity debate in the Euro crisis is about how supportive EU member states are to each other and under which conditions that helps to overcome the financial and economic crisis in the EU. The claims to solidarity during the Arab Spring in 2011, support for protesters in Turkey or the struggle for women's rights in Russia by the Punk Band Pussy Riot demonstrate the global appeal to solidarity as an issue to support marginalized actors in their struggle
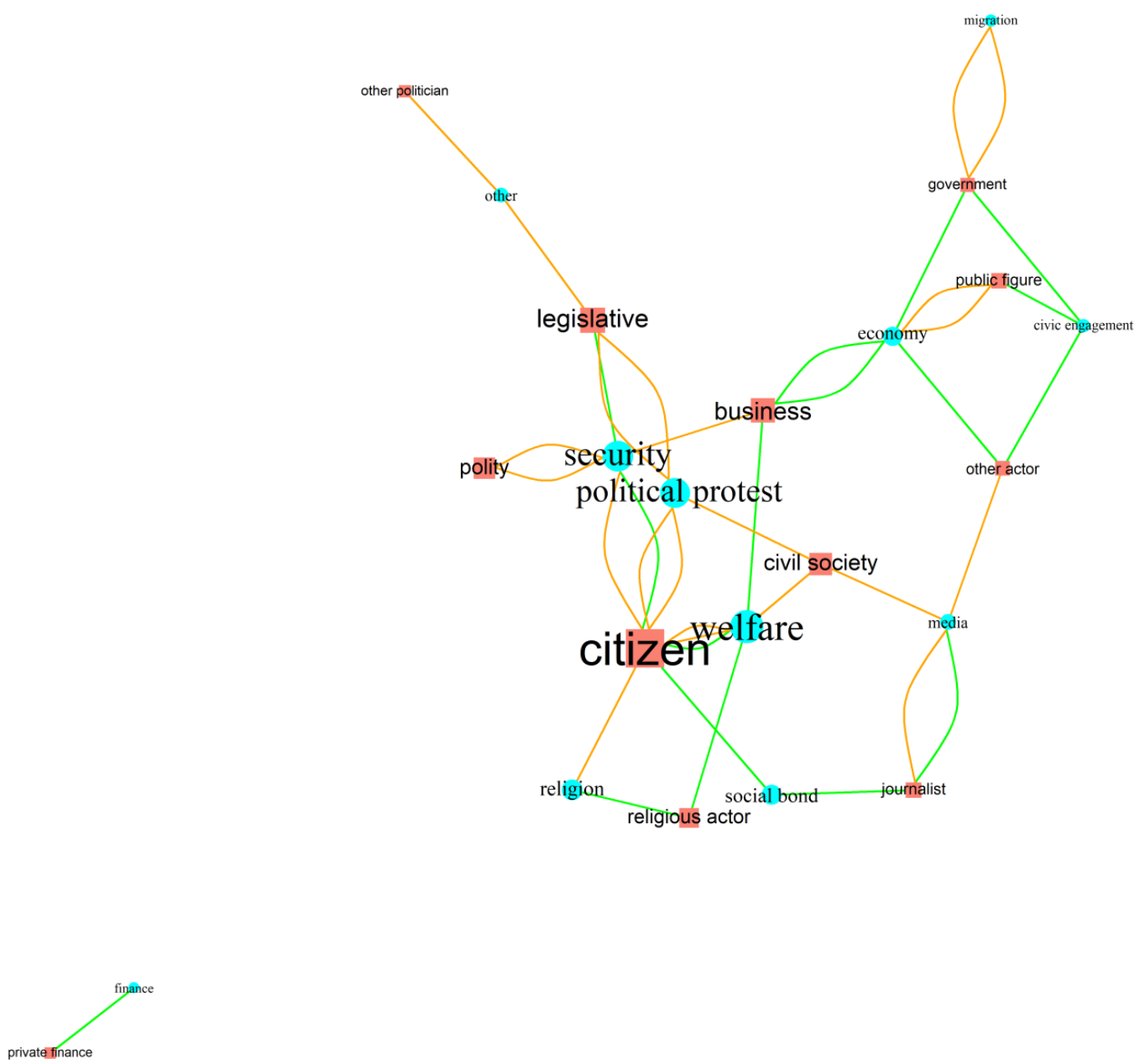

Figure 3. German solidarity discourse in German newspapers in 2008-2009. Note: The red squares are actor groups and the blue circles are issues. The bigger the node and the label, the more central the node is in the discourse network, based on eigenvector centrality. 


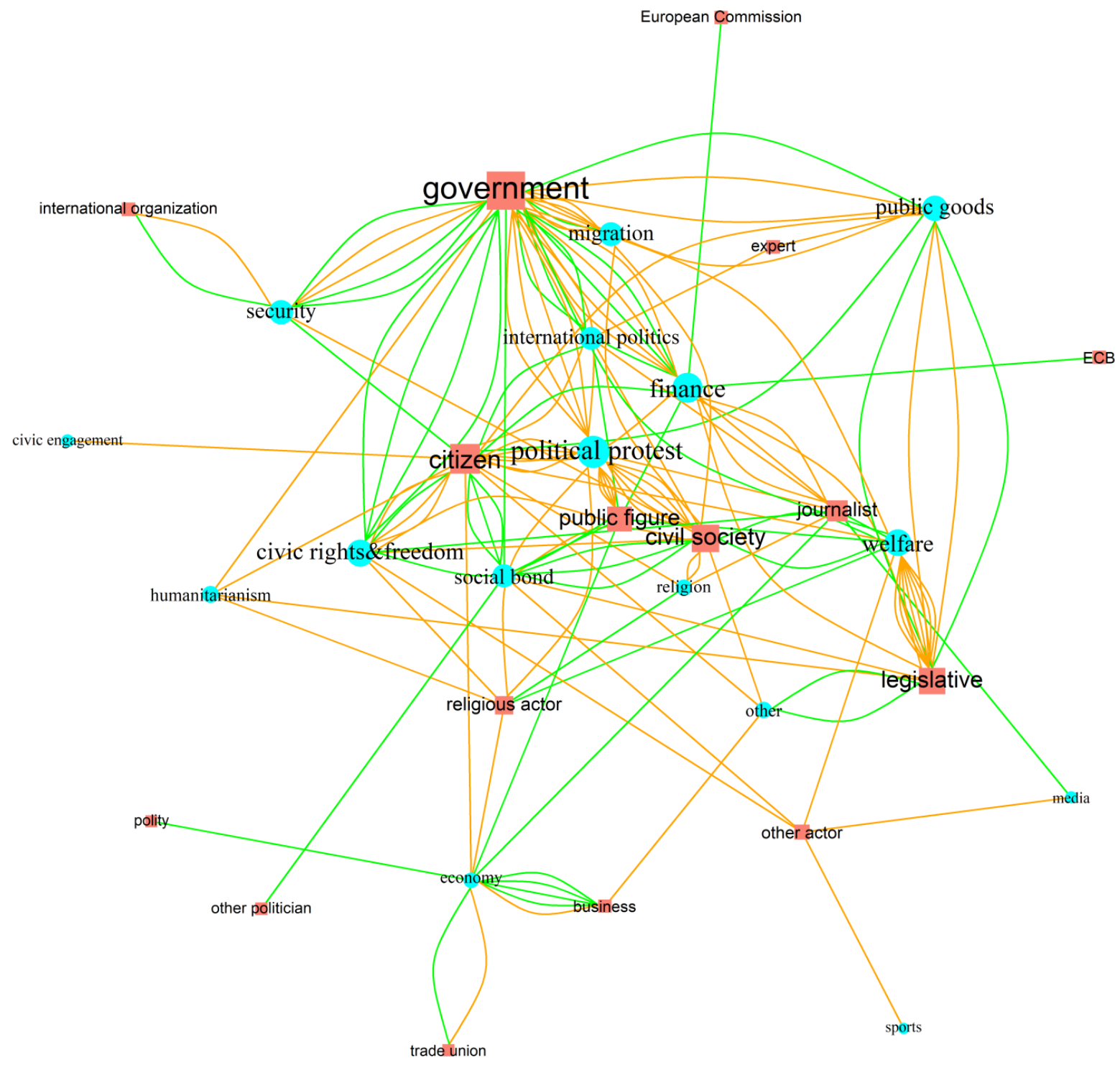

Figure 4. German solidarity discourse in German newspapers in 2010-2014. Note: The red squares are actor groups and the blue circles are issues. The bigger the node and the label, the more central the node is in the discourse network, based on eigenvector centrality.

against authoritarian political elites and for a more just and solidary society. This is supported by the strong presence of 'solidarity with' claims in these issues. Solidarity statements mainly refer to groups and actions that are beyond the claimants' own social groups and that articulate a connection with others and support them in their fight. Regarding the appearance of actors, we also demonstrate a shift towards institutionalized actors such as government and legislators, while citizens and civil society actors are still present in the solidarity discourse. Since the Euro crisis was predominantly managed on the intergovernmental EU level of national governments as well as in national parliaments (especially in the German Parliament), it comes as no surprise that national executives and parliamentarians become more visible in the second time period of the solidarity discourse.

The last time period (2015-2017, Figure 5) predominantly features three broad issues: the topic of migra- tion during Europe's migration crisis, calls for solidarity after terrorist attacks, and solidarity claims with the opposition in the Ukrainian and Syrian conflict. The migration crisis has dominated the public debate from summer 2015 onwards and placed the issue of migration and refugees at the top of public concern. Thus, questions of how to deal with incoming migrants in Europe, reforming the Dublin system and potentially establishing a refugee relocation scheme across EU member states put solidarity in the public spotlight. Solidarity calls are at the heart of this debate, because, on the one hand, solidarity with refugees is expressed by many different actors. Actors showed their sympathy and empathy and the media reported these in a favorable manner. On the other hand, solidarity was also present in the debate on how solidarity among the EU member states should be enacted by reforming the Dublin system or installing a relocation scheme that distributes refugees across the EU. 


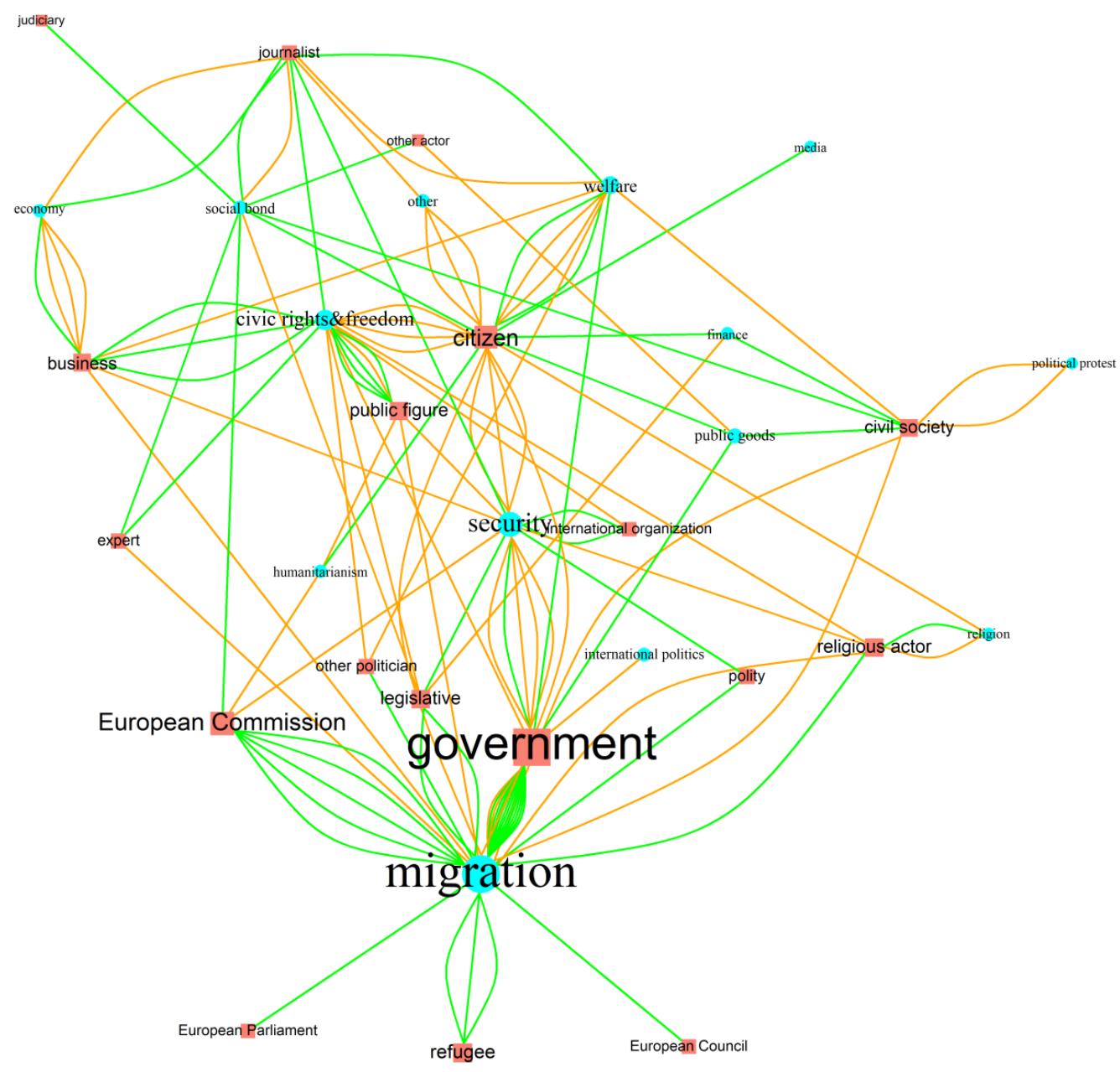

Figure 5. German solidary discourse in German newspapers in 2015-2017. Note: The red squares are actor groups and the blue circles are issues. The bigger the node and the label, the more central the node is in the discourse network, based on eigenvector centrality.

Hence, we demonstrate that the discussion of solidarity in the migration crisis is split into two debates: a 'solidarity with'-discussion regarding migrants and a 'solidarity among'-discussion regarding national governments in the EU.

Figure 6 displays the discursive oscillations in the appearance of issues by tracing the eigenvector centrality for each issue that has appeared at least once among the three highest ranked issues in one of the selected time periods. It shows a rather volatile discourse structure because the visibility of the selected issues changes quite strongly between the three time periods. We distinguish three main trends: a rise and fall of an issue, a steady increase, and a relatively stable presence of issues. Most of the selected issues match with the first trend. Political protest, finance and civic rights issues start from a low visibility in the solidarity discourse, then gain public attention due to different crises (global protest dynamic in authoritarian regimes, Euro crisis), but their visibility decreases again because the protests have succeeded (or not) or the Euro crisis has calmed down in the public debate. The second trend is linked to the in- creasing visibility of migration. While it was hardly an issue in the first time period, the increasing eigenvector centrality indicates the higher public awareness of solidary actions in relation to the migration issue and finally, the years 2015-2017 show the public omnipresence of solidarity claims. The last trend refers to welfare and security issues. While both issues have a high visibility in the first time period (2008-2009), their public presence decreases over time, but not as strongly as in the first trend. While security issues are linked to debates on solidarity among NATO members and showing solidarity after terrorist attacks, the welfare issue refers to social policy issues as well as discussions on supporting poor people and having fairer and more solidary welfare arrangements.

\section{Conclusion}

This article has investigated the solidarity discourse in German print media from 2008 to 2017 . Our main aim was to provide a longitudinal perspective on the use of solidarity as well as the issue and actor visibility in 


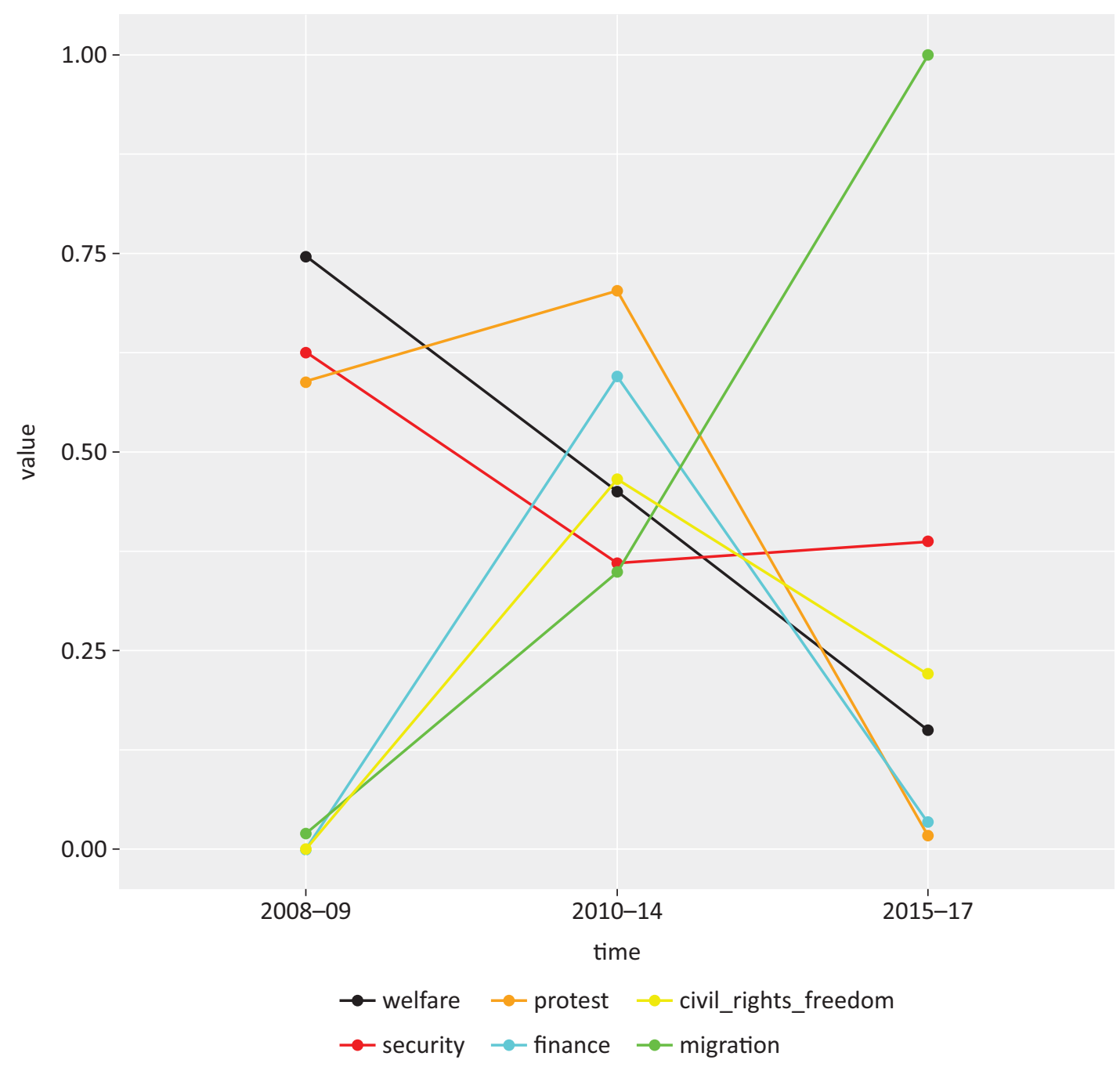

Figure 6. Most central issues in the German solidarity discourse in 2008-2017. Note: Only those issues are displayed which were among the three highest ranked issues (based on eigenvector centrality) in the respective time period. If an issue has a value of zero, then it is either very marginal or has not appeared in the respective time period.

public discourses. We conducted a discourse network analysis to map the interconnectedness of actor and issue appearance and identify the presence of different types of solidarity, namely 'solidarity among' and 'solidarity with.'

The descriptive results show that the term solidarity is used far more often by left-leaning newspapers in contrast to conservative newspapers. This suggests that the term is not 'empty' but rather carries different meanings. This finding is in line with historical research showing that solidarity developed as a pivotal political value and is one of the key concepts in current political affairs (Stjernø, 2009).

Reflecting our theoretical expectations, we discuss our three main findings. First, the solidarity discourse in German media predominantly follows the similar media logic that previous studies have shown regarding the dominance of national executives in newspapers and the weak visibility of international and European actors in national public spheres (Koopmans, 2007; Lahusen et al., 2016). The continuing presence of citizens and civil society groups in the solidarity discourse is, however, a unique finding. It underlines the practice and use of solidarity in citizens' communication and behavior. Solidarity is an elitist concept with a strong 'normative baggage,' but it also has an everyday meaning to nonacademic citizens who may participate in a demonstration, who may criticize increasing social inequalities or who may demand more solidary actions from political actors. This finding contributes to the normative debate on the Europeanization of the public sphere and how noninstitutionalized actors might play a crucial role in this process (Liebert, 2009; Statham \& Trenz, 2013).

Second, solidarity is a crisis-dependent concept in the public discourse. In years of turmoil, solidarity is used in public discourse to make sense of a crisis and mobilize the public. If a broader crisis perception exists, as in the Euro crisis or migration crisis, the solidarity debate centers around crucial issues such as finance, migration or political protest and most of the actors refer to them. If this is not the case, as we have shown in the first time period (2008-2009), then the 
solidarity debate is rather fragmented and actors and issues are less connected to each other. One reason why the Global Recession has not sparked a debate on solidarity in Germany might be that the US was at the center of attention and that the German government acted quickly to reassure German citizens that they will not lose money by bailing out German banks (e.g., HypoRealEstate or Commerzbank). Hence, the public conflict over whether solidarity was needed did not receive attention in 2008-2009. Nonetheless, and during the Euro crisis, we demonstrated that the debate on solidarity came to the fore.

Third, solidarity is context-sensitive. We underlined this by differentiating between 'solidarity with' and 'solidarity among' as two key solidarity relations. While both types of solidarity relations (44\% to $56 \%$ ) are used in the German solidarity discourse, we highlight that issues such as political protest or humanitarianism favor 'solidarity with'-statements, namely supporting protests in various countries and different social movements across the globe. Conversely, social bond issues or civic engagement-which, however, are rarely discussed in the overall discourse-show a tendency towards 'solidarity among'-statements. These claims are targeted towards the in-group and supposedly increase the loyalty among the group members. The migration issue tends towards 'solidarity with'-relations in the public debate, but a discursive divide regarding the use by actors can be identified: While government actors almost exclusively refer to 'solidarity-among'-relations in their statements on migration, other actors prefer the use of 'solidarity with' in their public claims. The former type predominantly refers to the solidarity debate among members of the $\mathrm{EU}$ and the question of whether a solidary and fair relocation scheme among the EU countries should be implemented. The latter type expresses the expected support of refugees and asylum seekers in Europe's migration crisis. Hence, our findings suggest that the debate on migration is explicitly split into two different types of solidarity.

We acknowledge that the study bears some limitations in terms of comparability, sampled data and methodology. From a comparative perspective, analyzing only the German case limits the generalizability of the results. Future research should use comparative research designs to detect potential differences between national contexts. From a data perspective, our study only investigated daily quality newspapers. This sample arguably covers a rather small portion and elitistcentered part of the public sphere. We are well aware of this limitation. However, since quality media strongly influence and mobilize the public, and since most of the actors try to be as visible as possible in these quality media outlets, our decision to focus on these media is justified. Nevertheless, future studies should analyze other forms of offline and online communication on solidarity such as blogs, social networking sites or parliamentary debates to get a better understanding of the meaning and use of solidarity in public discourses. From a methodological perspective, the discourse network approach showed its applicability beyond its utility for policy debates as previous studies have shown (Leifeld, 2016; Leifeld \& Haunss, 2012). It emphasizes the dynamics and interrelations between actor appearance and issue visibility. However, the discourse network approach also made it necessary to work with aggregated codes for the actors such as government or civil society. Otherwise, the discourse networks would have shown a large number of nodes that only appear once or twice in the whole time period, visualizing a rather sparse network. Public debates on contested concepts such as solidarity do not have this policy discourse structure with clear, identifiable, and a rather limited number of policy opponents as well as distinctive policy conflicts. Thus, our analyses of the public debate might provide another methodological challenge for the discourse network analysis, when it attempts to capture a rather volatile and dynamic public discourse in future studies.

Tracing the meaning of concepts such as solidarity in media debates over time is highly relevant in order to understand the dynamics of public discourses and to make sense of the different meanings that concepts might contain. We have demonstrated that the solidarity debate is influenced by crises, but is not entirely determined by them, and this finding might be scrutinized in future studies in greater detail.

\section{Acknowledgments}

The authors would like to thank the participants of the seminar "Discourses on Solidarity" held in 2018 at the University of Düsseldorf as well as the anonymous reviewers and the Academic Editor Philip Leifeld for detailed comments and suggestions on the manuscript. We also acknowledge financial support by Stiftung Universität Hildesheim.

\section{Conflict of Interests}

The authors declare no conflict of interests.

\section{Supplementary Material}

Supplementary material for this article is available online in the format provided by the authors (unedited).

\section{References}

Althammer, J. (2019). Solidarity: From small communities to global societies. In J. Althammer, B. Neumärker, \& U. Nothelle-Wildfeuer (Eds.), Solidarity in open societies (pp. 5-23). Berlin: Springer.

Auer, S. (2014). The limits of transnational solidarity and the Eurozone crisis in Germany, Ireland and Slovakia. Perspectives on European Politics and Society, 15(3), 322-334. https://doi.org/10.1080/15705854. 2014.912400 
Banting, K. G., \& Kymlicka, W. (Eds.). (2017). The strains of commitment: The political sources of solidarity in diverse societies. Oxford: Oxford University Press.

Bayertz, K. (1999). Four uses of solidarity. In K. Bayertz (Ed.), Solidarity (pp. 3-28). Berlin: Springer.

Bierhoff, H. W., \& Küpper, B. (1999). Social psychology of solidarity. In K. Bayertz (Ed.), Solidarity (pp. 133-156). Berlin: Springer.

Bonacich, P. (1987). Power and centrality: A family of measures. American Journal of Sociology, 9(5), 1170-1182.

Brändle, V. K., Eisele, O., \& Trenz, H.-J. (2019). Contesting European solidarity during the "refugee crisis": A comparative investigation of media claims in Denmark, Germany, Greece and Italy. Mass Communication and Society, 22(6), 708-732. https://doi.org/ 10.1080/15205436.2019.1674877

Ciornei, I., \& Recchi, E. (2017). At the source of European solidarity: Assessing the effects of cross-border practices and political attitudes. JCMS: Journal of Common Market Studies, 55(3), 468-485. https://doi.org/ 10.1111/jcms.12507

Closa, C., \& Maatsch, A. (2014). In a spirit of solidarity? Justifying the European Financial Stability Facility (EFSF) in national parliamentary debates. JCMS: Journal of Common Market Studies, 52(4), 826-842. https://doi.org/10.1111/jcms.12119

Dahlgren, P. (2002). In search of the talkative public: Media, deliberative democracy and civic culture. Javnost: The Public, 9(3), 5-25. https://doi.org/ 10.1080/13183222.2002.11008804

de Beer, P., \& Koster, F. (Eds.). (2009). Sticking together or falling apart? Solidarity in an era of individualization and globalization. Amsterdam: Amsterdam University Press.

Della Porta, D. (Ed.). (2018). Solidarity mobilizations in the 'refugee crisis': Contentious moves. London: Palgrave Macmillan.

Durkheim, E. (1965). The division of labor in society (2nd ed.). Washington, DC: Free Press.

Eilders, C. (2002). Conflict and consonance in media opinion: Political positions of five German quality newspapers. European Journal of Communication, 17(1), 25-63.

Gelissen, J. (2000). Popular support for institutionalised solidarity: A comparison between European welfare states. International Journal of Social Welfare, 9(4), 285-300. https://doi.org/10.1111/1468-2397.00140

Gerhards, J., Lengfeld, H., Ignácz, Z. S., Kley, F. K., \& Priem, M. (2020). European solidarity in times of crisis: Insights from a thirteen-country survey. Abingdon: Routledge.

Gouldner, A. W. (1960). The norm of reciprocity: A preliminary statement. American Sociological Review, 25(2), 161-178.

Grimmel, A., \& Giang, S. M. (Eds.). (2017). Solidarity in the European Union: A fundamental value in crisis. Berlin: Springer.
Habermas, J. (2006). Political communication in media society: Does democracy still enjoy an epistemic dimension? The impact of normative theory on empirical research. Communication Theory, 16(4), 411-426. https://doi.org/10.1111/j.1468-2885.2006.00280.x

Hechter, M. (1988). Principles of group solidarity. Berkeley, CA: University of California Press.

IVW. (2019). Informationsgemeinschaft zur Feststellung der Verbreitung von Werbeträgern e.V.: Quartalsauflagen. IVW. Retrieved from http://www.ivw.de/ aw/print/qa

Kleinen-von Königslöw, K., Post, S., \& Schäfer, M. S. (2019). How news media (de-)legitimize national and international climate politics: A content analysis of newspaper coverage in five countries. International Communication Gazette, 81(6/8), 518-540. https:// doi.org/10.1177/1748048518825092

Kolers, A. H. (2012). Dynamics of solidarity. Journal of Political Philosophy, 20(4), 365-383. https://doi.org/ 10.1111/j.1467-9760.2010.00391.x

Koopmans, R. (2007). Who inhabits the European public sphere? Winners and losers, supporters and opponents in Europeanised political debates. European Journal of Political Research, 46(2), 183-210. https:// doi.org/10.1111/j.1475-6765.2006.00691.x

Koopmans, R., \& Statham, P. (1999). Political claims analysis: Integrating protest event and political discourse approaches. Mobilization: An International Journal, 4(1), 203-221.

Lahusen, C., \& Grasso, M. (Eds.). (2018). Solidarity in Europe: Citizens' responses in times of crisis. London: Palgrave Macmillan.

Lahusen, C., Kousis, M., Kiess, J., \& Paschou, M. (2016). Political claims and discourse formations: A comparative account on Germany and Greece in the Eurozone crisis. Politics \& Policy, 44(3), 525-552. https:// doi.org/10.1111/polp.12162

Leifeld, P. (2016). Policy debates as dynamic networks: German pension politics and privatization discourse. Frankfurt: Campus.

Leifeld, P., \& Haunss, S. (2012). Political discourse networks and the conflict over software patents in Europe. European Journal of Political Research, 51(3), 382-409. https://doi.org/10.1111/j.14756765.2011.02003.x

Liebert, U. (2009). The contentious role of civil society in reconstituting democracy in the European Union. Policy and Society, 28(1), 71-86. https://doi.org/ 10.1016/j.polsoc.2009.02.008

Lindenberg, S. (1998). Solidarity, its microfoundation and macrodependence: A framing approach. In P. Doreian \& T. J. Fararo (Eds.), The problem of solidarity: Theories and models (pp. 61-112). New York, NY: Gordon and Breach.

Luengo, M., \& Ihlebæk, K. A. (2019). Journalism, solidarity and the civil sphere: The case of Charlie Hebdo. European Journal of Communication, 34(3), 286-299. https://doi.org/10.1177/0267323119844411 
Michailidou, A., \& Trenz, H.-J. (2018). European solidarity in times of crisis: Towards differentiated integration (ARENA Working Paper 05/2018). Oslo: ARENA Centre for European Studies.

O'Neill, O. (2002). Towards justice and virtue: A constructive account of practical reasoning. Cambridge: Cambridge University Press.

Sangiovanni, A. (2015). Solidarity as joint action. Journal of Applied Philosophy, 32(4), 340-359. https:// doi.org/10.1111/japp.12130

Sierp, A., \& Karner, C. (2017). National stereotypes in the context of the European crisis. National Identities, 19(1), 1-9. https://doi.org/10.1080/14608944.2016. 1209646

Statham, P., \& Trenz, H.-J. (2013). The politicization of Europe: Contesting the constitution in the mass media. Abingdon: Routledge.

Stjernø, S. (2009). Solidarity in Europe: The history of an idea. Cambridge: Cambridge University Press.

Taylor, A. E. (2015). Solidarity: Obligations and expressions. Journal of Political Philosophy, 23(2), 128-145. https://doi.org/10.1111/jopp.12035

Thome, H. (1999). Solidarity: Theoretical perspectives for empirical research. In K. Bayertz (Ed.), Solidarity (pp. 101-131). Berlin: Springer.

Thorbjørnsrud, K., \& Ustad Figenschou, T. (2016). Do marginalized sources matter? A comparative analysis of irregular migrant voice in Western media. Journalism Studies, 17(3), 337-355. https://doi.org/ 10.1080/1461670X.2014.987549

Tranow, U. (2019). Solidarity as a system of norms. In J. Althammer, B. Neumärker, \& U. NothelleWildfeuer (Eds.), Solidarity in open societies (pp. 25-55). Berlin: Springer. https://doi.org/10.1007/ 978-3-658-23641-0_3

van Oorschot, W. (2000). Who should get what, and why? On deservingness criteria and the conditionality of solidarity among the public. Policy \& Politics, 28(1), 33-48. https://doi.org/10.1332/0305573002500811

van Oorschot, W., Arts, W., \& Halman, L. (2005). Welfare state effects on social capital and informal solidarity in the European Union: Evidence from the 1999/2000 European values study. Policy \& Politics, 33(1), 33-54. https://doi.org/10.1332/0305573052708474

Van Parijs, P. (2017). Solidarity, diversity and social justice. In K. G. Banting \& W. Kymlicka (Eds.), The strains of commitment: The political sources of solidarity in diverse societies (pp. 420-426). Oxford: Oxford University Press.

Wallaschek, S. (2019a). Solidarity in Europe in times of crisis. Journal of European Integration, 41(2), 257-263. https://doi.org/10.1080/07036337.2019. 1546980

Wallaschek, S. (2019b). Contested solidarity in the Euro crisis and Europe's migration crisis: A discourse network analysis. Journal of European Public Policy. https://doi.org/10.1080/13501763.2019.1659844

Wallaschek, S. (2020a). Framing solidarity in the Euro crisis: A comparison of the German and Irish media discourse. New Political Economy, 25(2), 231-247. https://doi.org/10.1080/13563467.2019.1586864

Wallaschek, S. (2020b). The discursive construction of solidarity: Analysing public claims in Europe's migration crisis. Political Studies, 68(1), 74-92. https://doi. org/10.1177/0032321719831585

Wildt, A. (1999). Solidarity: Its history and contemporary definition. In K. Bayertz (Ed.), Solidarity (pp. 209-220). Berlin: Springer. https://doi.org/10.1007/ 978-94-015-9245-1_11

Williams, A. E., \& Toula, C. M. (2017). Solidarity framing at the union of national and transnational Public spheres. Journalism Studies, 18(12), 1576-1592. https://doi.org/10.1080/1461670X.2015.1134274

\section{About the Authors}

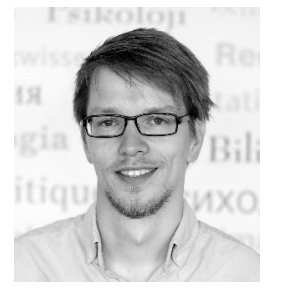

Stefan Wallaschek is a Post-Doctoral Researcher at the Institute of Social Sciences and works in the interdisciplinary research group SOLDISK at the University of Hildesheim. He received his PhD from the University of Bremen in 2019 and wrote his dissertation on Mapping Solidarity in Europe. Discourse Networks in the Euro Crisis and Europe's Migration Crisis. His research interests include European politics, political communication, European political sociology as well as the study of solidarity.

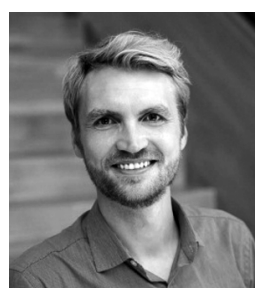

Christopher Starke works as a Post-Doc for political communication at the University of Düsseldorf. $\mathrm{He}$ is also affiliated with the Düsseldorf Institute for Internet and Democracy (DIID), the Center of Advanced Internet Studies (CAIS) and the Heine Center for Artificial Intelligence and Data Science (HeiCAD). He obtained his PhD from the University of Münster in 2018. His research interest includes European solidarity, algorithmic fairness, political trust and corruption. He is also the co-founder and host of KickBack, The Global Anticorruption Podcast. 


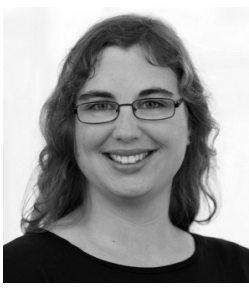

Carlotta Brüning is a Student Research Assistant and Assistant Lecturer at the University of Düsseldorf, with a focus on data analysis. She received her BA degree in Social Sciences from the University of Düsseldorf and is currently pursuing a Msc degree in Sociology and Social Research at the University of Cologne. Her research interests include social inequality, migration, network analyses and political communication. 